\section{Tropical Journal of Pathology and Microbiology}

\title{
Study of Acute Transfusion Reactions in a tertiary care hospital
}

\author{
R. Gotekar Y. ${ }^{1}$, Khade A. ${ }^{2 *}$ \\ DOI: https://doi.org/10.17511/jopm.2020.i06.07 \\ 1 Yashodhara R. Gotekar, MD (Pathology), Associate Professor, Department of Pathology, Bharati Vidyapeeth (Deemed to be University) \\ Medical College and Hospital, Sangli, Maharashtra, India. \\ 2* Amruta Khade, MD, Bharati Vidyapeeth (Deemed to be University) Medical College and Hospital, Sangli, Maharashtra, India.
}

Introduction: Blood transfusion is an effective way of correcting the hematological needs of patients, but adverse effects do occur during or after transfusion. These adverse events associated with the transfusion of whole blood or one of its components are known as transfusion reactions. Aim: To study the frequency and type of Acute Transfusion Reactions (ATRs) occurred in patients receiving blood transfusions. Materials and Methods: This retrospective observational study was done to know acute transfusion reactions reported to Bharati Vidyapeeth (Deemed to be University) Medical College and Hospital, Blood Bank, Sangli over a period of 5 years (January 2015-December 2019).All ATRs related to whole blood and blood components were analyzed and classified on the basis of their clinical features and laboratory tests. Results: ATRs during or after blood transfusion reported during the five year period were $77(0.21 \%)$ out of 35,593 units of blood /blood components transfused. ATRs reported were febrile non hemolytic transfusion reactions (FNHTR) 46 $(59.74 \%)$, allergic Reactions 29 (37.66\%), anaphylactic reactions $2(2.59 \%)$ in order of frequency. Conclusion: The majority of ATRs were FNHTRs followed by allergic reactions.

Keywords: Acute transfusion reactions, Blood component, FNHTR, Hemovigilance, Whole blood

Corresponding Author

Amruta Khade, MD, Bharati Vidyapeeth (Deemed to be University) Medical College and Hospital, Sangli, Maharashtra, India.

Email: amukhade54@gmail.com
How to Cite this Article

To Browse

Gotekar YR, Khade A. Study of Acute Transfusion

Reactions in a tertiary care hospital. Trop J Pathol

Microbiol. 2020;6(6):410-416.

Available From

https://pathology.medresearch.in/index.php/jopm/ar

ticle/view/477

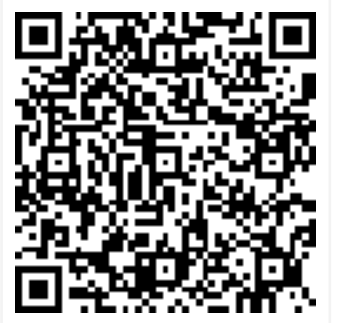

\section{Introduction}

Blood transfusion is the term used to describe the therapeutic use of whole blood and blood products. Modern-day blood transfusion therapy is a relatively safe procedure because of the discovery of blood groups by Karl Landsteiner in 1901 [1]. Transfusions even though are lifesaving in critically ill patients and having clinical benefits in their treatments, also carries considerable risk to

Manuscript Received

2020-07-25

Conflict of Interest No
Review Round

Funding

Nil
Review Round 2
2020-08-20

Ethical Approval Yes
The patient [2]. So consider it as a doubleedged weapon it should be used judiciously. The inherent risks embedded in transfusion varies in severity from minor to lifethreatening [3]. One of the risks involved in transfusion is the risk of getting the noninfectious complications of blood transfusion [4]. These non-infectious complications are known as adverse transfusion reactions and classified into Acute Transfusion Reactions (manifesting within $24 \mathrm{hrs}$ ) and delayed trans-

(c) 2020 by Yashodhara R. Gotekar, Amruta Khade and Published by Siddharth Health Research and Social Welfare Society. This is an Open Access article licensed under a Creative Commons Attribution 4.0 International License https://creativecommons.org/licenses/by/4.0/ unported [CC BY 4.0].

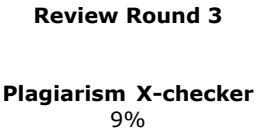

Review Round 3

Plagiarism X-checker $9 \%$

Accepted 2020-08-26

Note 
Fusion reactions (manifesting after 24 hrs ).

A transfusion reaction is defined as any untoward event occurring during or after the transfusion of blood or blood components [5]. ATRs remain a matter of concern as the incidence of acute blood transfusion reactions is estimated to be $0.2-10 \%$ and is responsible for mortality in 1 per 250,000. Causes of ATRs include human errors, ABO incompatibility, alloimmunization, bacterial contamination, and immunomodulation phenomenon. A reaction can present with nonspecific, often overlapping symptoms. The signs and symptoms of an acute transfusion reaction range from itching, urticaria (hives), fever, and chills. Respiratory distress, high-grade fever, hypotension, and red-colored urine indicate a more serious reaction [6]. Close observation at the start of the transfusion of each blood unit is, therefore, essential [7]. Access to adequate and safe blood transfusion facilities is an integral part of the basic health care delivery system [8]. The goal of hemovigilance is to improve the safety and quality of blood transfusion services as acute transfusion reactions are nonpredictable.

Hemovigilance is defined as a set of surveillance procedures covering the whole transfusion chain from collection of blood and its components to follow-up of its recipients, intended to collect and access its information on unexpected or undesirable effects resulting from therapeutic use of labile blood products and to prevent their occurrence and recurrence [9].

Observing the standard blood transfusion protocols in pre-transfusion, during transfusion, and posttransfusion period can help to prevent transfusion reactions. Hence the blood replacement therapy demands a considerable degree of expertise for maximum recipient protection [10]. Thorough knowledge can help in preventing the occurrence of ATR and dealing with possible unwanted events in clinical management [11]. A complete analysis of adverse events is the most important objective of a hemovigilance system [12]. Identification of the adverse reactions will help in haemovigilance to reduce their incidence and to make blood transfusion procedure safe [13]. For this purpose, it is essential to establish a system for monitoring, recording, and reporting adverse reactions caused by blood transfusion in the hospital.

The present study was conducted in Bharati hospital Blood Bank to know the frequency and type of acute
Transfusion reactions (ATRs) observed in the patients who have received the blood transfusion.

\section{Materials and Methods}

\section{Setting:}

Duration of Study: 3 months (1-month data collection, 2-month data analysis)

Study Design: Retrospective analytical Study

Sampling Method: Purposive

Sample size: Medical records of 77 ATRs reported to the Blood Bank of Bharati Hospital, Sangli

Inclusion Criteria: ATRs occurred in all patients who had received a blood transfusion at our hospital within a 5 year period from 1 January 2015 to 31 December 2019 within 24 hours of Blood or blood components transfused.

Exclusion Criteria: patients who received blood from outside blood banks.

\section{Data Collection Procedure:}

The retrospective study was done after receiving approval from the Institutional Ethical Committee, with approval letter BV (DU) MC\&H /Sangli/IEC/384/2020

A total of 77 ATRs are noted during the study period amongst 35,593 units of blood transfused from Bharati blood bank in Bharati Hospital Sangli. Details of all ATRs were recorded.

The predesigned "transfusion adverse reaction reporting form" was filled by the treating physician and reported to the Blood Bank was studied in detail and entered in the excel chart.

All transfusion reactions that were reported during the period of five years (January 2015- December 2019) were investigated and analyzed as per the departmental protocol which was prepared in accordance with the guidelines by Transfusion Medicine Technical Manual (DGHS) Second Edition 2003 [14].

The transfusion record contains the patient's identification, type of transfusion component, date of issue, date of transfusion, start time, completed time, the reaction occurred, type of reaction allergic or pyrogenic or hemolytic and remark if any. After noting this following protocol was followed.

Patient identification (name, age, sex, hospital no, ward, unit) were rechecked both on the vial and 
Compatibility card to rule out the possibility of wrong sampling or bedside transposition.

Details of patient records and blood unit transfused are checked to rule out any clerical error.

The compatibility card with the remaining blood bag and blood transfusion set was inspected for signs of deterioration i.e. clot, discoloration, hemolysis, or foul smell.

Post transfusion blood sample from the vein of the opposite side and urine sample was asked to send to the blood bank for further investigations. $-2 \mathrm{ml}$ of a blood sample in EDTA, $3 \mathrm{ml}$ of a blood sample in the plain along with the first void urine sample after blood transfusion. ABO and Rh typing on patient's pre and post-transfusion samples and reconfirmation of $A B O$ and $\mathrm{Rh}$ type of blood unit transfused

Compatibility testing was repeated with pre and post-transfusion patients samples.

The patient's post-transfusion blood sample was checked for:

- Hemolysis

- Serum bilirubin (direct and indirect)

- A peripheral smear examination was done for signs of hemolysis.

- The patients' post-transfusion urine sample was examined for haematuria and hemoglobinuria.

- Direct Coombs Test (DCT) and irregular antibody screening were done on patients' pre and post-transfusion samples.

- Sample from the blood unit was sent to the microbiology department for culture.

- Renal Function Test

- Febrile non- hemolytic reaction (FNHTRs) was defined as a temperature increase of more than 1-degree Cabove 37'Cand/or chills associated with blood transfusion without any other explanation.

- Allergic reactions were associated with cutaneous or systemic manifestations.

- Immune hemolytic reactions were diagnosed based on the clinical /laboratory evidence of hemolysis and positive direct agglutination test (DAT). Non-immune hemolytic reactions due to mechanical destruction of RBCs were suspected when the patient had hemolysis but negative DAT.
- Transfusion-related acute lung injury (TRALI) was characterized by hypoxemia, respiratory failure, hypotension, and fever in the absence of cardiac failure.

\section{Results}

ATRs during or after blood transfusion reported to the blood bank in 77 patients $(0.18 \%)$ out of 35,593 units of blood transfused. As per the gender distribution of ATR cases are 30 (38.96\%) males and $47(61.03 \%)$ females (Table 1$)$.

Table-1: Gender-wise distribution of ATRs
(n=77).
\begin{tabular}{|l|l|c|l|c|}
\hline Total ATRs & Number of male & $\%$ & Number of Female & $\%$ \\
\hline 77 & 30 & $38.96 \%$ & 47 & $61.03 \%$ \\
\hline
\end{tabular}

The age of the study patients ranged between 1day to 80 years. As per the gender distribution 47 $(61.03 \%)$ ATRs were seen in females. The females in the age group of 21-40 years were found to have more (24 i.e. $51.06 \%$ ) ATRs (Table 2)

Table-2: The distribution of ATRs based on age and gender $(n=77)$.

\begin{tabular}{|l|l|l|l|c|}
\hline Age (Years) & Male $(\mathrm{n}=\mathbf{3 0})$ & $\%$ & Female $(\mathbf{n}=\mathbf{4 7})$ & $\%$ \\
\hline $0-20$ & 10 & 33.33 & 10 & 21.27 \\
\hline $21-40$ & 09 & 30 & 24 & 51.06 \\
\hline $41-60$ & 08 & 26.66 & 06 & 12.76 \\
\hline $61-80$ & 03 & 10 & 06 & 12.76 \\
\hline Total & 30 & & 47 & \\
\hline
\end{tabular}

The incidence of Febrile Non-Hemolytic Transfusion Reactions (FNHTR) was reported in 46 (59.74\%) patients, allergic reactions in 29 (37.66\%) patients, anaphylactic reactions in $02(2.5 \%)$ patients in order of frequency (Table 3).

Table-3: The distribution of type of ATRs $(n=77)$.

\begin{tabular}{|l|l|l|}
\hline \multicolumn{1}{|c|}{ Year (2015-2019) } & Total ATRs & \multicolumn{1}{c|}{$\%$} \\
\hline FNHTR (Febrile non- haemolytic reaction) & 46 & 59.74 \\
\hline Allergic reactions & 29 & 37.66 \\
\hline Acute Non -immune hemolysis & 0 & 0 \\
\hline TACO (Transfusion associated circulatory overload) & 0 & 0 \\
\hline Anaphylactic reactions & 02 & 2.59 \\
\hline TRALI (Transfusion-related acute lung injury) & 0 & 0 \\
\hline Total & 77 & 100 \\
\hline
\end{tabular}

The number of blood component units transfusion done were 14,017 RBCs, 3294 whole blood (WB), 7602 platelets, 10256 fresh frozen plasma ( FFP), 72 Cryoprecipitate and 352 single donor platelet ( SDP.) Of all the reported ATRs, (i.e77ATRs) 38 $(49.35 \%)$ occurred with transfusion of packed red 
Blood cells (PRBC, $) 15$ (20.77\%) occurred with whole blood ( WB), 13 (16.88\%) with Fresh Frozen Plasma ( FFP) and 10 ( $12.98 \%)$ with platelets
Transfusions in order of frequency. Not a single case of ATRs was reported after the transfusion of cryoprecipitate and single donor platelet. (Table 4)

Table-4: Type of transfusion reactions according to a type of component transfused ( $n=77$ ).

\begin{tabular}{|c|c|c|c|c|c|c|c|c|}
\hline $\begin{array}{l}\text { Type of components } \\
\text { transfused and } \\
\text { quantity }\end{array}$ & $\begin{array}{l}\text { FNHTR (Febrile } \\
\text { non-hemolytic } \\
\text { reaction) }\end{array}$ & $\left|\begin{array}{c}\text { Allergic } \\
\text { reactio } \\
\text { ns }\end{array}\right|$ & $\begin{array}{l}\text { Acute Non - } \\
\text { immune } \\
\text { hemolysis }\end{array}$ & $\begin{array}{l}\text { TACO (Transfusion- } \\
\text { associated circulatory } \\
\text { overload) }\end{array}$ & $\begin{array}{c}\text { Anaphylac } \\
\text { tic } \\
\text { Reaction }\end{array}$ & $\begin{array}{l}\text { TRALI (Transfusion- } \\
\text { related acute lung } \\
\text { injury }\end{array}$ & DHTR & Total \\
\hline $\begin{array}{l}\text { Whole blood (WB) } \\
3294\end{array}$ & 08 & 07 & 00 & 00 & 01 & 00 & 00 & 16 \\
\hline $\begin{array}{l}\text { Packed cell RBC } \\
\text { (PRBC) } 14,017\end{array}$ & 21 & 16 & 00 & 00 & 01 & 00 & 00 & 38 \\
\hline $\begin{array}{l}\text { Platelet concentrate } \\
7602\end{array}$ & 07 & 03 & 00 & 00 & 00 & 00 & 00 & 10 \\
\hline $\begin{array}{l}\text { Fresh Frozen Plasma } \\
\text { (FFP) } 10256\end{array}$ & 10 & 03 & 00 & 00 & 00 & 00 & 00 & 13 \\
\hline Cryoprecipitate 72 & 00 & 00 & 00 & 00 & 00 & 00 & 00 & 00 \\
\hline SDP 352 & 00 & 00 & 00 & 00 & 00 & 00 & 00 & 00 \\
\hline Total 35593 & 46 & 29 & 00 & 00 & 02 & 00 & 00 & 77 \\
\hline
\end{tabular}

\section{Categorization of ATRs}

All the cases in the present study were acute transfusion reactions.

FNHTRA total of $46(59.74 \%)$ patients had signs and symptoms of FNHTR. The age group of patients with FNHTR ranged from 1 month to 80 years. Out of 46 patients, 29 patients received transfusion with WB/PRBCs, 7 received with Platelet concentrate, and 10 received FFP transfusion. Fever was the most common presenting symptom (50.9\%) followed by chills and rigors in (40.9\%)of patients.

Allergic reactions were observed in 29 (37.66 \%) patients. Age range from 22days to 62years. Of the 29 patients, 23 patients had WB/PRBCs transfusion and 03 were transfused with Platelet concentrate and 03 had FFP transfusion. The most common presentation of allergic reactions was urticaria $(17.2 \%)$, followed by a rash $(13.6 \%)$.

Anaphylactic reactions were seen in 2 (2.59\%) patients. Both were females, age 30 years, and 22 years and they were transfused with RBCs.

\section{Discussion}

ATRs are unprecedented risks associated with allogenic blood transfusions. Clinical reporting is the only source of information about the incidence of transfusion reactions. Identification of the acute blood transfusion reactions will help in taking appropriate steps for haemovigilance. An ideal
Hemovigilance system is designed to detect, gather, and analyze unexpected or undesirable effects associated with transfusion [15]. In India, the haemovigilance program was launched on 10 th December 2012.

In the present study, all the reactions reported were acute. The frequency of acute transfusion events in the present study was $0.21 \%$ (77 out of 35,593 ). In a similar study by Bhattacharya et al incidence of adverse transfusion reaction was $0.18 \%$ (105 reactions out of 56,503 units of blood and blood component transfused [1] and in another study by Pahuja et al the incidence of adverse transfusion reaction was $0.19 \%$ ( 314 out of $1,60,973$ units of blood and blood component transfused) [12]. This rate is similar to other published results, varying from $0.22 \%$ to $0.42 \%$ transfusion events.

In the present study of ATRs, it was found females were more affected $47(61.03 \%)$ than males 30 (38. $96 \%$ ) similar to the study by Sidhu et al [16] and same with another study by Sharma DK the frequency of ATRs was more in females (59.4\%) than in males (40.6\%) [8]. However, Kumar et al. [13] in their study found males to be more affected than females. In the present study transfusion reactions noted in female patients in the age group of 21-40 years were maximum 24 , (i.e. $51.06 \%$ ) than their male counterparts.(9, i.e. $30 \%)$.

FNHTR (Febrile Non-Hemolytic Transfusion Reactions) 
Data on the incidence of FNHTR varies greatly in the literature. Possible reasons for this variation include differences in recording of symptoms by the bedside staff, case ascertainment, and the use of pretransfusion medications to control fever $[17,18]$. In the present study incidence of FNHTR was 46 (59.74 $\%)$. The incidence of FNHTR may be high because PRBCs were not leuco depleted. Pre-storage WBC reduction significantly reduced the rate of FNHTRs to Packed Cells and packed red blood cells (PRBCs) [6]. The present study correlated well with the study done by Chowdhury et al. [2], Khalid et al. [4], and Bhattacharya et al. [1] which also showed the incidence of FNHTR from 37.2 to $62.5 \%$ in their studies (Table 5). Allergic reactions: Allergic reactions were observed in 29 (37.66 \%)patients in the present study compared with studies done in Delhi $(55.1 \%)$ by Kumar et al [13] and Iran $(49.2 \%)$ by Payendeh et al [17]. Allergic transfusion reactions accounted for $17 \%$ (273 of 1613) of the transfusion reactions in the previous studies [1923].

Anaphylactic reactions: The incidence of anaphylactic reactions have been found to be 2 $(2.59 \%)$ in the present study compared to $(5.1 \%)$, by Kumar et al [13].

TACO (Transfusion-associated circulatory overload) in the present study not a single case of TACO was found but studies estimating the risks of hypervolemia due to transfusion reported as 0.31 $0.42 / 1000$ recipients of transfusion $[23,24.25]$.

Table-5: Comparison of the present study with other studies with respect to the type of ATRs seen.

\begin{tabular}{|l|l|l|l|l|}
\hline Name of study & $\begin{array}{c}\text { FNHTR } \\
(\%)\end{array}$ & \multicolumn{1}{|c|}{ Allergic } & $\begin{array}{l}\text { AHTR } \\
\text { reactions (\%) }\end{array}$ & $\begin{array}{c}\text { Anaphylactic } \\
\text { Reactions (\%) }\end{array}$ \\
\hline Chowdhury et al [2] & 62.5 & 25 & - & - \\
\hline Khalid et al [4] & 41.9 & 34.4 & 1.8 & - \\
\hline $\begin{array}{l}\text { Bhattacharya et al } \\
{[1]}\end{array}$ & 41 & 34 & 8.56 & - \\
\hline Pahuja et al [12] & 54.7 & 41.4 & 1.2 & 2.4 \\
\hline Kumar et al [13] & 35.7 & 55.1 & 2.6 & - \\
\hline Payendeh et al [17] & 37.2 & 49.2 & - & - \\
\hline $\begin{array}{l}\text { Venkatachalapathy } \\
\text { TS et al. [19] }\end{array}$ & 43.75 & 50 & - & - \\
\hline Riti Tushar [21] & 55.8 & 41.5 & - & 2.5 \\
\hline Present study & $59.74 \%$ & $37.66 \%$ & 00 & $2.59 \%$ \\
\hline
\end{tabular}

TRALI (Transfusion-related acute lung injury)

The risk factors of severe transfusion-related diseases including TRALI and anaphylactic shock
Depend on the patient's disease, number of transfusions, and history of adverse events [18]. Literature search has revealed case reports [26] and haemovigilance reports [27] of TRALI, but there was not a single case observed in the present study.

Table-6: Comparison of the present study with other studies conducted in relation to Transfusion reactions according to the type of components transfused.

\begin{tabular}{|l|l|l|l|}
\hline \multicolumn{1}{|c|}{ Name of study } & \multicolumn{1}{|c|}{$\begin{array}{c}\text { WB and PRBC } \\
(\%)\end{array}$} & \multicolumn{1}{|c|}{$\begin{array}{c}\text { Platelets } \\
(\%)\end{array}$} & FFP (\%) \\
\hline Bhattacharya et al [1] & 82.8 & 11.4 & 5.7 \\
\hline Pahuja et al [12] & 93.63 & 3.82 & 2.54 \\
\hline Kumar et al [13] & 42.8 & 37.75 & 19.38 \\
\hline Payandeh et al [17] & 45.7 & 20.3 & 30.51 \\
\hline $\begin{array}{l}\text { Venkatachalapathy TS et al } \\
{[19]}\end{array}$ & 95.83 & - & 2.08 \\
\hline Haslina et al [20] & 76.5 & 6.57 & 16.9 \\
\hline Sinha RTK [21] & 68.83 & 12.98 & 18.18 \\
\hline Present Study $(\mathrm{n}=77)$ & $54(77.12 \%)$ & $10(1.2 \%)$ & $13(16.88$ \\
& & & $\%)$ \\
\hline
\end{tabular}

In the present study, the highest percentage of reactions were seen with whole blood and packed red blood cells ( PRBCs) which were 54 $(77.21 \%)$.This rate is similar to other published results, varying from $42.8 \%$ to $95.83 \%$ $[1,11,13,17,19,20,21]$. Adverse transfusion reactions seen with Platelets were 10 (1.2\%) which was similar $(0.7 \%)$ to a study by Khalid $S$ [4] and with FFP were $13(16.88 \%)$ which was similar $(19.38 \%)$ to study by Kumar et al [13].

So, to establish a good hemovigilance system and attainment towards the goal of safe transfusion, resident doctors and nurses in the hospital ward should be made aware of the importance of safe blood transfusion process. Reporting of all major and minor transfusion events and analysis to avoid ATRs.

\section{Limitations}

In this study, it was noted that only acute transfusion reactions were reported during the first 24 hours after transfusion. Underreporting of minor transfusion reactions by medical/nursing staff can be a possibility.

\section{Conclusion}

The majority of ATRs were FNHTRs followed by allergic reactions. 
Recommendation: It is recommended that the blood bank staff should take the responsibility to educate and to give adequate knowledge to the medical and paramedical staff who work in the wards about the prevention of ATRs. To achieve proper hemovigilance a checklist before starting blood transfusion must be made mandatory.

\section{What does the study add to the existing knowledge}

Skilled, trained, and dedicated manpower working in the blood bank, and reporting of all adverse events can have a good haemovigilance system in reducing the incidence of ATRs to a minimum.

\section{Author's contribution}

Dr. Yashodhara Gotekar: Collection of data, preparation of a manuscript for introduction, material and methods, and preparation of a manuscript for discussion.

Dr. Amruta Khade: Corresponding and second author: Data analysis, preparation of results, a compilation of references, correspondence with the editor.

\section{Acknowledgments}

The authors express their sincere thanks to the blood bank technical staff for help in the collection of the data.

\section{Reference}

01. Bhattacharya P, Marwaha N, Dhawan HK, Roy P, Sharma RR. Transfusion-Related Adverse, Events At The Tertiary Care Center In North India- An Institutional Hemovigilance Effort. Asian J Transfus Sci. 2011;5(2)164-170. Available at [Article] [Crossref]

02. Chowdhury FS, Biswas J, Siddiqui MAE, Hoque MM, Adnan SK. Transfusion Reaction Among The Blood Recipient - A Study Of 120 Cases. J Dhaka Med Coll. 2008;17(2)67-71. doi: $10.3329 /$ jdmc.v17i2.6585 [Crossref]

03. Sahu S, Hemlata and Verma A. Adverse events related to blood transfusion. Indian J Anaesthes. $2014 ; 58(5) 543-551$.

doi: $10.4103 / 0019-5049.144650$ [Crossref]
04. Khalid S, Usman $M$ and Khurshid M. Acute Transfusion Reactions Encountered In Patients At A Tertiary Care Center. J Pak Med Assoc. $2010 ; 60(10) 832-836$.

[Crossref]

05. Chavan S K, Patil G, Rajopadhye P. Adverse Blood Transfusion Reactions at Tertiary Care Hospital. Int J Res Med Sci. 2016;4(6)24022407.

doi: $10.18203 / 2320-6012 . i j r m s 20161822$ [Crossref]

06. Suddock JT, Crookston KP. Transfusion reactions. Stat Pearls Publishing. 2019 Jul 27.

[Crossref]

07. Adverse Effects Of Transfusion. Clinical Transfusion Practice Guidelines for Medical Interns. World Health Organization. 26. [Crossref]

08. Sharma DK, Dutta S, Gupta A. Study Of Acute Transfusion Reactions In A Teaching Hospital Of Sikkim- A Hemovigilance Initiative. Indian J Pharmacol. 2015;47(4)370-374. doi: 10.4103/0253-7613.161257 [Crossref]

09. Vartak UC, Shewale R, Vartak S, Faizal F and Majethia N. Adverse Reactions of Blood Transfusion- A Study In A Tertiary Care Hospital. Int J Sci Study. 2016;4(2)90-94.

doi: $10.17354 /$ ijss/2016/259 [Crossref]

10. Saran RK, editor. Transfusion medicinetechnical manual, Directorate General of Health Services, Ministry of Health and Family Welfare. Government of India. 2003.

[Crossref]

11. Pahuja S, Puri V, Mahajan G, Gupta P, Jain M. Reporting adverse transfusion reactions- $A$ retrospective study from tertiary care hospital from New Delhi, India. Asian J Transfus Sci. 2017; 11(1)6-12. doi: $10.4103 / 0973-6247.200779$ [Crossref]

12. Kumar $P$, Thapliyal $R$, Coshic $P$ and Chatterjee $K$. Retrospective Evaluation Of Adverse Transfusion Reactions Following Blood Product Transfusion From A Tertiary Care Hospital- A Preliminary Step Towards Hemovigilance. Asian J Transfus Sci. $2013 ; 7(2) 109-115$.

doi: $10.4103 / 0973-6247.115564$ [Crossref] 
13. Bhardwaj K. Transfusion Guide For Clinicians. JP Medical LTD. 2012;125.

[Crossref]

14. Bharucha Z. Introduction To Transfusion Medicine. DK Publishers. 1990;308.

[Crossref]

15. Faber JC. Haemovigilance Around The World. Vox Sang. 2002;83(1):71-76.

doi: $10.1111 /$ j.1423-0410.2002.tb05271.x [Crossref]

16. Sidhu M, Meenia R, Yasmeen I and Akhtar N. A Study Oftransfusion Related Adverse Events At A Tertiary Care Centre In North India- An Initiative Towards Hemovigilance. Int J Advan Med. $2015 ; 2(3) 206-210$.

doi: 10.18203/2349-3933.ijam20150545 [Crossref]

17. Payandeh M, Zare ME, Kansestani AN, Pakdel $S F$, Jahanpour $F$, Yousefi $H$, et al. Descriptions of Acute Transfusion Reactions In The Teaching Hospitals Of Kermanshah University Of Medical Sciences, Iran. Int J Hematol Oncol Stem Cell Res. $2013 ; 7(2) 11-16$.

[Crossref]

18. Hatayama $\mathrm{Y}$, Matsumoto S, Hamada E, Kojima $\mathrm{N}$, Hara A, Hino $\mathrm{N}$, et al. Analysis of Acute Transfusion Reactions and Their Occurrence Times. Yonago Acta Med. 2018;61(1)87-90. doi: 10.33160/yam.2018.03.013 [Crossref]

19. Venkatachalapathy TS. A Prospective Audit of Blood Transfusion Reactions In Tertiary Care Hospital For The Use Of Blood And Blood Components. J Blood Disord Transfus. 2012;3(2)1-5.

DOI: $\quad 10.4172 / 2155-9864.1000118$ [Crossref]

20. Sinha RTK, Rai P, Dey A. A Study of Transfusion Related Adverse Events at a Tertiary Care Center in Central India- A Retrospective Evaluation. J Med Sci Health. 2016;2(3)6-12. doi: $10.46347 / j m s h .2016 . v 02 i 03.002$ [Crossref]
21. Haslina MNN, Fakhri MAM, Saw TH and Salamah AS. An Audit on Acute Transfusion Reaction In North Eastern Malaysia. Sch J Med. 2012;2(5)60-62.

[Crossref]

22. Domen RE and Hoeltge GA. Allergic Transfusion Reactions- An Evaluation of 273 Consecutive Reactions. Arch Pathol Lab Med. 2003; 127(3)316-320.

doi: $\quad 10.1043 / 0003-$ 9985(2003)127<0316:ATR>2.0.CO;2 [Crossref]

23. Robillard $P$ and Karl Itaj N. Incidence of Adverse Transfusion Reactions In The Quebec Hemovigilance System. Vox Sanguinis. $2002 ; 83 ; 120$.

[Crossref]

24. Popovsky MA and Taswell RF. Circulatory Overload- An Undiagnosed Consequence of Transfusion. Vox Sanguinis. 2002; 83; 469. [Crossref]

25. Haji AG, Sharma S, Vijaykumar DK, Paul J. Transfusion Related Acute Lung Injury Presenting With Acute Dyspnoea- A Case Report. J Med Case Rep. 2008;2;336.

doi: $10.1186 / 1752-1947-2-336$ [Crossref]

26. Chapman CE, Stainsby D, Jones H, Love E, Massev $E$, Win $N$, et al. Ten Years of Haemovigilance Reports of Transfusion Related Acute Lung Injuryin The United Kingdom And The Impact Of Preferential Use Of Male Donor Plasma. Transfus. 2009;49(3)440-452.

doi: $\quad 10.4097 / \mathrm{kjae} .2015 .68 .2 .101 \quad$ [Crossref]

27. Khoyumthem $P$, Rachandra K, Goswami S, Lyngdoh LN, Sharma AB, Singh AM. Acute Transfusion Reactions in A Tertiary Hospital- A 2-Year Retrospective Study. J Med Soc. 2018;32(1)47-50. doi: $10.4103 / j m s . j m s \_41 \_17$ [Crossref] 